\title{
Childhood Obesity Among Young Children Living in Poverty and Associations with Activity Level, Food Choices, and Parental Perceptions
}

Ashlee Cunningham

Follow this and additional works at: https://researchrepository.wvu.edu/etd

\section{Recommended Citation}

Cunningham, Ashlee, "Childhood Obesity Among Young Children Living in Poverty and Associations with Activity Level, Food Choices, and Parental Perceptions" (2016). Graduate Theses, Dissertations, and Problem Reports. 5419.

https://researchrepository.wvu.edu/etd/5419

This Thesis is protected by copyright and/or related rights. It has been brought to you by the The Research Repository @ WVU with permission from the rights-holder(s). You are free to use this Thesis in any way that is permitted by the copyright and related rights legislation that applies to your use. For other uses you must obtain permission from the rights-holder(s) directly, unless additional rights are indicated by a Creative Commons license in the record and/ or on the work itself. This Thesis has been accepted for inclusion in WVU Graduate Theses, Dissertations, and Problem Reports collection by an authorized administrator of The Research Repository @ WVU. For more information, please contact researchrepository@mail.wvu.edu. 
Childhood Obesity Among Young Children Living in Poverty and Associations with Activity Level, Food Choices, and Parental Perceptions

\title{
Ashlee Cunningham
}

\author{
Thesis submitted \\ to the College of Education and Human Services \\ at West Virginia University \\ in partial fulfillment of the requirements for the degree of \\ Master of Arts in \\ Educational Psychology \\ With an emphasis in Child Development and Family Studies
}

\author{
Suzanne Hartman, Ph.D., Co-Committee Chairperson \\ Jessica Troilo, Ph.D., Co-Committee Chairperson \\ Barbara Warash, Ed.D., Member
}

Department of Learning Sciences and Human Development

\author{
Morgantown, West Virginia \\ 2016
}

Keywords: obesity, poverty, parental perceptions, physical activity, food choice Copyright 2016 Ashlee Cunningham 


\title{
ABSTRACT \\ Childhood Obesity Among Young Children Living in Poverty and Associations with Activity Level, Food Choices, and Parental Perceptions
}

\begin{abstract}
Ashlee Cunningham
Young children living in poverty are exposed to a number of barriers in their environment that put them at risk for physical health problems, specifically obesity and increased BMI. Physical activity level, food choices, and parental perceptions of children's weight are barriers to healthy weight in children and can consequently lead to other future developmental problems. A population of low income, preschool aged children was examined using measures of child BMI, parental income, parental education, fast food consumption, amount of TV watched, and parental perceptions of children's weight. Findings showed child BMI was related to children watching more TV in a week, suggesting that low income children may be engaging in too much sedentary activity. There was also significance found in the relationship between parental perceptions of children's weight and their BMI, highlighting that parents in the current study were actually correct in perceiving their children's weight. Lastly, parental perceptions were also linked to the number of days in a week that children watched TV. This finding shows that parents who perceived their children as being overweight were also allowing their children to watch more TV than parents who perceived their children as being of average weight or underweight.
\end{abstract}




\section{Table of Contents}

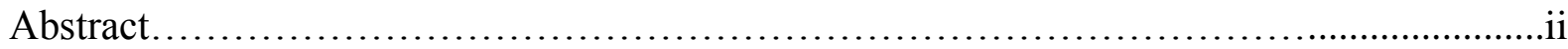

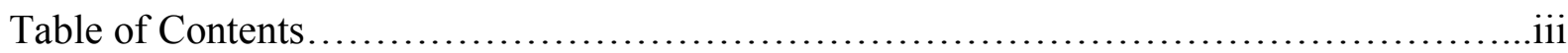

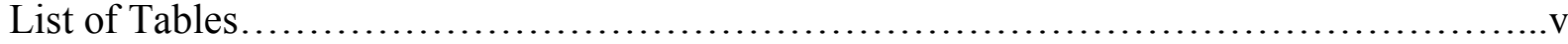

Chapter I: Introduction........................................................

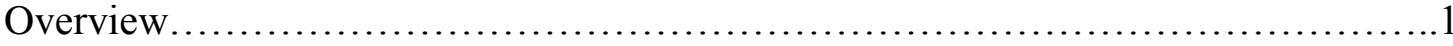

Research Questions........................................................5

Chapter II: Literature Review...................................................6

Bronfenbrenner's Ecological Theory.......................................

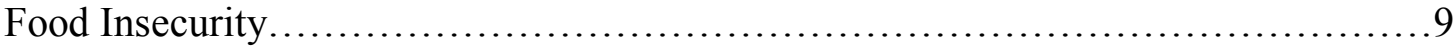

Food Access.................................................................. 10

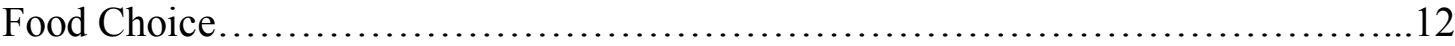

Fruit and Vegetable Consumption......................................... 15

Physical Activity......................................................... 16

Parental Perceptions..................................................... 17

Ecological System Levels and Variables of Physical Health.......................20

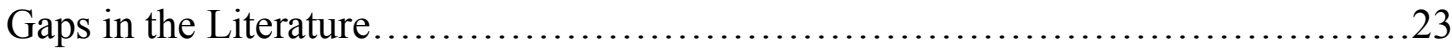

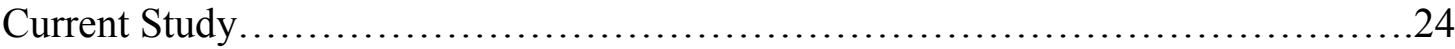

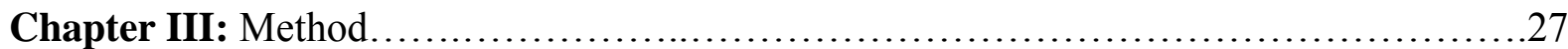

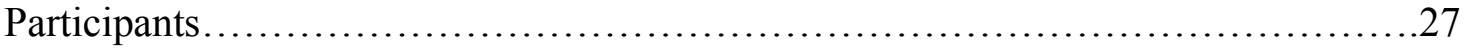

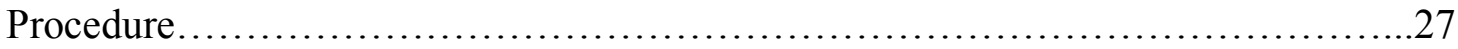

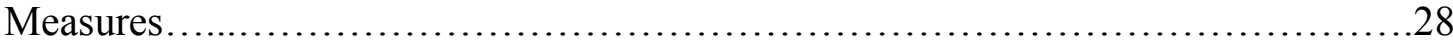

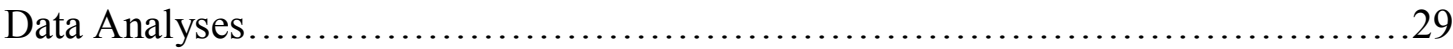

Chapter IV: Results..................................................... 31

Descriptive Statistics.................................................... 31

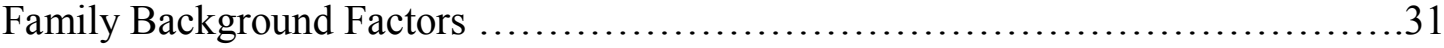

Child Behavioral Factors...................................................... 32

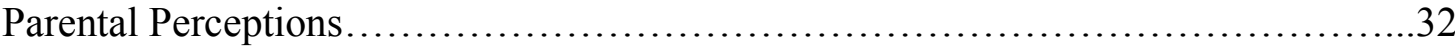

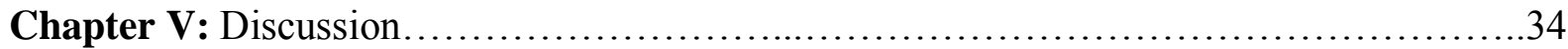

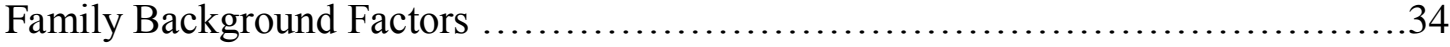


Child Behavioral Factors................................................ 36

Parental Perceptions.......................................................... 38

Limitations and Future Directions........................................41

Conclusions .......................................................... 42

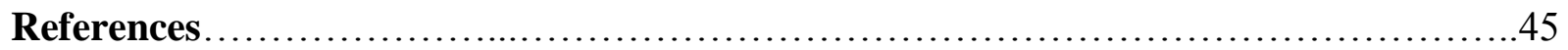

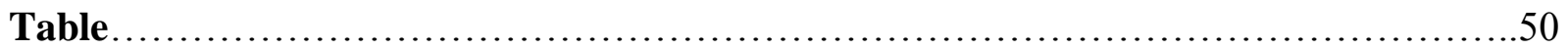




\section{List of Tables}

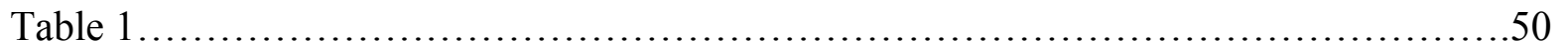




\section{Chapter I: Introduction}

This project investigated a number of factors that previous researchers have found can influence physical health at a young age, specifically, body mass index (BMI). These factors may negatively impact a sample of low income children ages 3-5. This project expanded on the existing area of research by focusing specifically on young children ages 3-5 from low income homes, which is a population of children who have not been included in prior research on overweight physical health. These influential factors include family background factors (income and education), child behavioral factors (consumption of fast food and television watching), and also parental perceptions of their children's weight status as underweight, average weight, or overweight. It is essential that we better understand how these factors influence children in poverty's BMI because these factors can influence negative health behaviors. A better understanding can also influence patterns that may impact future health outcomes and put children at risk for unhealthy growth and development.

\section{Overview}

There are undoubtedly barriers that families living in poverty face in regards to their overall physical health because of social and environmental factors in their everyday lives. The most salient obstacle these families face in regards to their health and health behaviors is income (Drewnowski \& Darmon, 2005; French, Story \& Jeffery, 2001; Nackers \& Appelhans, 2013). Price is one of the many barriers that parents face in accessing and choosing healthy foods for themselves and their families. French et al., (2001) note that healthy foods tend to be significantly more expensive than unhealthy, high fat foods. Families choosing less healthy foods because of their income are at a disadvantage when it comes to their health (Drewnowski \& Darmon, 2005; French et al., 2001; Nackers \& Appelhans, 2013). Another obstacle parent's face 
in regards to their health is their education level. Individuals with lower levels of educational attainment are not as knowledgeable about factors that influence their health and weight status such as making healthy food choices, reading nutrition labels, and judging the weight status of their family members (Baughcum, Chamberlin, Deeks, Powers \& Whitaker, 2000; Doolen, Alpert \& Miller, 2009; Hudson, McGloin \& McConnon, 2011).

The varying degrees of food access and food choices that families and children make can also have a strong influence on their overall health. This statement holds especially true in regards to the low income population. Grutzmacher and Gross (2011) discussed the negative impact that the lack of access to nutritional foods can have on children's overall health. According to the authors, those who live in food insecure homes lacking the types and amount of food needed to be healthy, are more likely to experience things such as poor diet quality, decreased cognitive development, and higher body fat percentage in adulthood, and emotional and behavioral problems (Grutzmacher \& Gross, 2011). Specifically, varying degrees of food access and choice can lead to negative outcomes for children's body mass index (BMI). Reportedly, children who are food insecure are at a significantly greater risk of becoming overweight or obese when compared to children from food secure homes (Larson et al., 2011; Metallinos-Karsaras, Must \& Gorman, 2012). Additionally, economically disadvantaged neighborhoods typically do not have a lot to offer in regards to full service grocery stores that sell fresh fruits and vegetables (Salois, 2011). Instead, low income neighborhoods are highly populated with convenience stores and fast foods chains (Salois, 2011). The increased amount of convenience stores and fast food restaurants in low income neighborhoods can lead these families to make unhealthy food choices, ultimately putting them at risk for higher BMI. 
Not only are fast food restaurants more prevalent in low income neighborhoods, influencing families and children's food choices and consequently their BMI, but fast food is also significantly cheaper in price than some healthy food alternatives such as fresh fruits and vegetables (Drenowski \& Darmon, 2005). Unlike preparing healthy meals in the home, fast food also requires little to no preparation, supplies, storage, clean up, and time making it easier and more appealing for busy, working families. Further, travel to fast food establishments is easier for families living in these areas. Families living in poverty may choose to eat and serve fast food to their children for any of the above reasons, which consequently can have a negative impact on their BMI and physical health (Drewnowski \& Darmon, 2005; Nackers \& Appelhans, 2013).

Low income families physical activities and the amount of TV they watch also impact their BMIs. Researchers suggest that children who play outside less frequently also stay inside more to watch television and play video games (French, Story \& Jeffery, 2001). Children who are spending most of their time watching television are not getting enough daily exercise, and this negatively impacts their overall health and BMI (French et al., 2001). According to the National Association for Sport and Physical Education (2002), preschool aged children should engage in some type of physical activity for at least two hours every day in order to promote healthy body growth and development. Children who engage in this regular exercise reduce their likelihood of becoming overweight or obese (Collings, Brage, Ridgway, Harvey, Godfrey et al., 2013).

Parental perceptions of their child's weight can also play a significant role in the overall health of their child, and especially their weight and BMI. How parents see their children in regards to weight status can influence the types of foods they provide for and encourage their children to eat (Hudson et al., 2011). If parents perceive their children as average or 
underweight, they may provide unhealthy food options for their children or not pay attention to what they are eating as a result of this judgement (Campbell, Williams, Hampton \& Wake, 2006; Doolen et al., 2009). According to research, it is very common for parents to misperceive their child's weight status by judging them to be of a healthy weight when they are not (Doolen et al., 2009; Hudson et al., 2012; Maynard, Galuska, Blanck \& Serdula, 2003). These misperceptions can show negative consequences for the child's weight and BMI.

Similarly, parental perceptions of children's weight status can influence the amount of physical activity their children engage in and the amount of television parents allow their children to watch, which in turn may impact the child's BMI. Parents are a strong influence on their children's weight and health related behaviors and activities (Veitch, Hume, Salmon, Crawford \& Ball, 2011). Veitch et al., (2011) found that mothers believed that their encouragement of physical activity had a strong influence on whether their children actually engaged in regular physical activity and exercise or not. Parents who are misperceiving their children's weight may not recognize that their children need encouragement to participate in more physical activities as opposed to watching television or playing video games.

For the purpose of this study, the researcher is investigating the proposed link between BMI and several family background factors, child behaviors as well as parental perceptions of their child's weight among a sample of low income, preschool aged children. The family background factors included parental income and education. The child behaviors investigated were amount of television watched and amount of fast food consumed in a weeks' time. Lastly, parent perceptions of their children's BMI was also be examined in relation to the child's actual BMI and behaviors. The following research questions guided this study on low-income children's health: 
1. Family Background and Child BMI:

a. Will child BMI be higher among children of parents with lower annual income compared to children whose parents have greater annual income?

b. Will child BMI be higher among children whose parents have lower educational attainment compared to children whose parents have greater educational attainment?

2. Child Behaviors and BMI:

a. Will child BMI be higher among children who consume fast food more often in a weeks' time than peers who consume less?

b. Will child BMI be higher among children who watch more TV in a weeks' time compared to peers who watch less?

3. Parental Perceptions, Behaviors, and Child BMI:

a. Will children's BMI be different by parents' perceptions of their children's weight as under, average, or over weight?

b. Will the number of times that children consume fast food in a weeks' time differ by parents' ratings of their children's weight?

c. Will the number of days in a week that children watch more TV differ by parents' ratings of their children's weight? 


\section{Chapter II: Literature Review}

This project investigated multiple factors that may impact the BMI of young children living in poverty. The following literature review discusses the barriers that poverty imposes on children's food options and physical activity as well as parents' education, food knowledge, and perceptions. These barriers were discussed in how they may impact children's health and BMI. These factors include: food security, food access, food choice, and physical activity as well as parental education and perceptions of health and health related behaviors. These factors can be understood through the theoretical lens of Bronfenbrenner's Ecological Theory, which is discussed in the following review of literature. To conclude, several noteworthy gaps are discussed as well as an introduction into the current study.

\section{Literature Review}

Poverty can yield negative consequences for children in a variety of ways. In 2013 the poverty rate was $14.5 \%$, which was 2 percentage points higher than in 2007 (United States Census Bureau, 2015). Poverty can negatively impact cognitive, language, and socioemotional development in early childhood. Research has shown that one of the greatest impacts poverty has on a child's development is on their cognitive functioning (McLoyd, 1998). Children from consistently impoverished families score 9 points or lower on IQ assessments when compared to non-impoverished children (Duncan, Brooks-Gunn \& Klebanov, 1994). Children living in poverty also exhibit scores that are 3 to 4 points or higher on internalizing and externalizing behavior problem indexes (Duncan et al., 1994). Additionally, children living in impoverished homes often exhibit lower levels of language functioning and academic achievement because of a lack of stimulation in the home environment (McLoyd, 1998). 
Cognitive, language, and behavioral problems are not the only aspects of development that poverty can impact in early childhood. Poverty is associated with issues of varying types and degrees for children (McLoyd, 1990). Specifically, poverty can impact physical development. Physical development is especially important to look at during early childhood because of the tremendous growth that occurs at this time in brain and associated cognitive development (Markant \& Thomas, 2013). The frontal lobes grow rapidly in children between the ages of 3 and 6 with this area of the brain involved in planning, organizing and attentional control, which are important for learning and school (Shaw et al., 2006).

Additionally, a lot of bodily growth occurs during this time (Centers for Disease Control and Prevention, 2000). On average, children grow around 2.5 inches and gain anywhere between five and seven pounds during early childhood (Centers for Disease Control and Prevention, 2000). However, impacts of poverty on bodily growth are not as well examined as the impact poverty can have on brain and cognitive development (Duncan et al., 1994; McLoyd, 1998). Early bodily growth is important to study because it can be predictive of future health and health related behaviors. In fact, early growth and size are related to an increased risk of obesity during childhood and later years (Hawkins \& Law, 2006). The preschool period, specifically, has been pinpointed as a critical time for physical development (McGrady, Mitchell, Theodore, Sersion \& Holtzapple, 2010). Childhood obesity can be harmful to children because it can lead to future health problems such as adulthood obesity, heart disease, hypertension, depression, and cancer (Patrick \& Nicklas, 2005). If ignored, childhood obesity can have long lasting consequences on children's health and overall physical development.

\section{Bronfenbrenner's Ecological Theory}


The issue of obesity among children living in poverty is a topic that is underrepresented in existing research. Impoverished children being at risk of becoming overweight or obese can be examined via Bronfenbrenner's Ecological Model (1994). Urie Bronfenbrenner proposes that in order to fully understand human development, one's entire ecological system must be considered (Bronfenbrenner, 1994). A person's ecological system is made up of five subsystems in which growth and development occur. An ecological system starts with an individual at the center of the system and then spans outwards into five larger more encompassing systems. The first of the five subsystems is the microsystem. The microsystem includes activities, relationships, and roles experienced by the individual in their immediate environment such as friends, family, school, and work (Bronfenbrenner, 1994). The next subsystem is the mesosystem. The mesosystem includes interactions between two or more components of the microsystem such as the interaction between the family system and the child's school (Bronfenbrenner, 1994). Spanning out from the mesosystem is the exosystem. The exosystem includes events and experiences in an individual's life that indirectly influences them such as their parent's work environment (Bronfenbrenner, 1994). The macrosystem is the fourth of the five subsystems. The macrosystem consists of the culture an individual lives in. This may include specific customs, belief systems, and other cultural values specific to the individual (Bronfenbrenner, 1994). The last system is the chronosystem. The chronosystem looks at changes over time in terms of the individual as well as the individual's environment such as differences in technology, war or peace time, or generational values and customs (Bronfenbrenner, 1994). The topics discussed in the following literature review on factors that may influence impoverished children's health and BMI all fall along Bronfenbrenner's ecological model. Utilizing Bronfenbrenner's ecological model helps to clarify how the influencing factors trickle down through several levels on the ecological model to 
impact children's health and BMI as an end result. The following review discusses each topic with mention of which ecological system or systems it falls into and ends with an overview explaining how the factors fall along the ecological model.

\section{Food Insecurity}

Children living in poverty suffer from a lack of resources that children from other socioeconomic backgrounds do not experience. Parents and caretakers of low income or impoverished families may struggle to provide basic needs for their children. Specifically, poverty may restrict parents from providing enough food that is also sufficiently nutritional for their children. When parents are not able to provide their children with the amount of food and types of food necessary to maintain a healthy and active lifestyle, they are said to be food insecure (Grutzmacher \& Gross, 2011; Larson, Story \& Nelson, 2011; Metallinos-Karsaras et al., 2012; Nackers \& Appelhans, 2013). Food insecurity has become a major issue in low income households across the United States. According to Nackers and Appelhans (2013) nearly $15 \%$ of U.S. families in 2011 suffered from a lack of food security. In the same year, Grutzmacher and colleagues (2011) cited that roughly 3.7 million children experienced food insecurity in their families at some time. Food insecurity can restrict parents' food purchases, limiting them to purchase higher calorie foods at lower costs (Grutzmacher et al., 2011). These same financial constraints, in turn, restrict children from eating adequately nutritious meals at home (Grutzmacher, 2011).

Living in poverty and being food insecure can lead to serious health problems. Food insecurity has been found to be associated with childhood obesity. Specifically, research has cited a $22 \%$ increase in the risk of becoming overweight or obese when a child is food insecure (Metallinos-Katsaras et al., 2012). Compared to only 24\% of children from middle or high 
incomes, $33 \%$ of low income children were either overweight or obese while they were in preschool (Metallinos-Katsaras et al., 2012). Children from low income families typically consume foods that are higher in fat and sugar and lower in nutritional value. Reportedly, food insecure children eat fewer fruits and vegetables and consume more things such as fast food, sugary beverages, such as soda, and other energy dense foods when compared to children who are living in food secure homes (Nackers \& Appelhans, 2013). Children living in poverty and suffering from food insecurity are also less active than food secure children, which takes a major toll on physical development (Rose \& Bodor, 2005). These children often lack resources necessary to maintain an active lifestyle and frequently engage in sedentary behaviors instead of regular exercise (French et al., 2001). Previous researchers show that being food insecure influences eating and physical activity, which are both actions that take part in a children's immediate environment; thereby showing the influence of food insecurity on a child's microsystem. All these factors poses a risk for these children becoming overweight or obese.

\section{Food Access}

Maintaining a healthy diet has been grossly influenced by the number of resources a family has access to. All families do not have access to the same amount or types of foods. In low income neighborhoods, supermarkets and grocery stores are less common and convenience stores and fast food restaurants are more frequently found (Salois, 2011). Families living in low income or impoverished neighborhoods have less access to fresh fruits and vegetables and other healthy food options when shopping at convenience stores as opposed to full service supermarkets (Di Noia \& Byrd-Bredbenner, 2014). Convenience store density has also been found to be positively linked to childhood obesity in urban areas (Salois, 2011). Convenience stores are known for selling unhealthy foods such as candy, snacks, and soda and are also known 
to accept WIC in some areas of the United States (United States Department of Agriculture Food and Nutrition Service, 2016). WIC is a supplemental nutrition assistance program for low income women, infants, and children about half of food insecure families participate in WIC or another food and nutrition assistance program (Larson et al., 2011; United States Department of Agriculture Food and Nutrition Service, 2016). Low income families may be inclined to shop at convenience stores not only because they are densely populated in their neighborhoods but also because they accept WIC.

Another important consideration in regards to low income families accessing food is transportation. Low income families are less likely to have reliable means of transportation to get to and from full service supermarkets and grocery stores as frequently as they may need or like to as compared to other higher-income families (Larson et al., 2011). The limited variety in grocery shopping and the high density of nearby fast food restaurants and convenience stores in low income areas may lead families to eat outside of the home rather than cooking fresh ingredients that are typically higher in nutrients (Drewnowski \& Darmon, 2005). Drewnowski and Darmon (2005) call fast food placement in inner city neighborhoods strategic, stating that restaurant owners may place their establishments in low income areas because they know that families living in these areas do not have access to many other food healthful options. The authors use this to explain the lack of access to fresh produce among low income families.

The interaction of several key components together can influence a family's food access. Poverty in the home and the low income and low resource neighborhoods, which families are living in, can work together to influence families. The interaction between the density of food shopping outlets that provide mostly unhealthy food choices, such as fast food and convenience stores, and transportation can limit food access. Families that lack reliable means of 
transportation to and from grocery stores are likely to consume more unhealthy foods that can be purchased at nearby fast food restaurants or convenience stores. The interplay between all of these factors that exist in low income families' immediate environments, such as their home life and neighborhoods in the microsystem, influence each other and thus can be examined within the framework of the mesosystem.

\section{Food Choice}

Access to different varieties and amounts of foods can influence the choices families are making in their food purchases. While food access is influential, it is also important to examine what types of foods families are choosing even when they do have access to full service grocery stores and what is driving these decisions. Specifically, since low income families have less money and fewer resources to feed their children, nutritional value is often being overlooked compared to price, convenience, and shelf life (Nackers and Appelhans, 2013).

In neighborhoods high in poverty, price was the most important consideration parents made when purchasing food (Nackers \& Appelhans, 2013). Healthy foods are typically more expensive than unhealthy foods so not all consumers have the same degree of choice when it comes to food shopping for their families. In fact, energy dense foods that are higher in fat are purchased more by low income groups while fruits and vegetables are purchased more frequently by high income groups. Changing the price of specific foods may lead low income population to purchase of different, healthier foods (French et al., 2001).

The reason low income families more frequently consume high fat, energy dense foods may also be explained by the tendency of these types of food to be more easily prepared when compared to fresh fruits, vegetables, and other more nutritious alternatives (Drewnowski \& Darmon, 2005; Nackers and Appelhans, 2013). Among families who do prepare meals from 
scratch in the home, the meals prepared by food insecure families are typically less complex than those prepared by families where limited food is not an issue (Grutzmacher et al., 2011). This lack of complexity meant lower energy and nutrient meals with less fruits, vegetables, grains and proteins (Grutzmacher et al., 2011). A potential reason for the minimal complexity in home cooked meals among food insecure families could be that they lack the food preparation supplies needed, such as pots, pans, measuring cups, and cooking knives (Appelhans, Waring, Schneider \& Pogoto, 2014).

Similarly, food insecure families can also struggle to pay for basic necessities such as heat and electricity, which will also hinder the preparation of home cooked meals in that household (Appelhans et al., 2014). Without these basic supplies and resources, cooking becomes more effortful, time consuming and maybe even impossible meaning that for food insecure families home cooked meals may not be a viable option. Reportedly, children who live in homes that have more food preparation supplies and resources eat more complex home cooked meals, which are typically healthier and more nutritional (Appelhans et al., 2014; Grutzmacher et al., 2011). Taken together with similar research, these findings suggest that families that do not have the resources and supplies needed to prepare meals in the home are likely consuming more meals outside of the home in high-density fast food areas or at home prepared with minimal complexity (Appelhans et al., 2014) both of which are often high fat, energy dense meals. In addition to the higher cost and resources needed to cook nutrient dense foods, these foods typically have a shorter shelf life and require more time for preparation compared to energy dense foods. Nackers and Appelhans (2013) reported that parents with low food security had more meals that could be stored frozen as well as easily and quickly prepared in the microwave when compared to parents who were food secure. As opposed to junk foods such as 
chips, candy, and soda, fresh produce is not only more costly but often requires refrigeration and other preservation methods that may not be available to families living in poverty (Appelhans et al., 2014). Drewnowski and Darmon (2005) rate time convenience along with price as being one of the most important factors in making food choices among low income families. With the popularity of dollar menus at fast food restaurants, eating out is not only cheaper for some families but also less time consuming and requires no preservation and little clean up.

Lastly, nutrition may be overlooked when food shopping because people are not knowledgeable about nutrition facts or do not know how, have the time, or care to read a products' nutrition label. French et al. (2001) state that even though the use of nutrition labels while shopping is associated with a diet lower in fat, only about $66 \%$ of shoppers actually use them to make food choices. More specifically, low income parents are less likely to use nutrition labels while shopping and are also less aware of diet-related health problems (Grutzmacher \& Gross, 2011). Even among low income families that are knowledgeable about nutrition and may even use the nutrition labels, price, convenience and shelf life still seems to be more important factors in food choice while grocery shopping.

Examining food choice through an ecological lens is critical as preschool aged children are not the one's making these food choices, but these food choices take place within the developing child's exosystem and can likely impact their health and BMI. Bronfenbrenner (1994), describes the exosystem as being made of up of at least two interactions, one of which does not directly involve the developing children, but that results in events that indirectly influence them. As food choices and food purchasing decisions are tasks largely taken on by parents and often outside the home (ex. at the grocery store) where children are not directly involved, they are a part of the developing child's exosystem. The food choices are not directly 
made by the low income children but they impact their health through the food choices that their parents are making for them.

\section{Fruit and Vegetable Consumption}

Fruit and vegetables are an important part of maintaining a healthy diet and there are many benefits associated with their intake. Reduced risk of heart disease, stroke and cancer are some of the benefits associated with consuming fruits and vegetables (Di Noia \& ByrdBredbenner, 2014). Their intake may also help lower the risk of type 2 diabetes and aid in maintaining a healthy body weight (Di Noia \& Byrd-Bredbenner, 2014). Children who do not consume many fruits and vegetables such as low income children, may be denied these benefits. Income influences intake of fruits and vegetables but it is unclear how income can determine how many fruits and vegetables children consume (Di Noia \& Byrd-Bredbenner, 2014). Lack of access and/or lack of knowledge about the benefits of fruit and vegetable intake may partially account for the reasons low income youth are less likely to consume fruits and vegetables (Di Noia \& Byrd-Bredbenner, 2014). Price has been determined as a major factor in choosing whether or not children are consuming fruits and vegetables but even among those low income children that are consuming some fruit and vegetable items, the least costly items are consumed the most of all. Orange juice, apple juice, canned tomatoes and potato chips are a few of the less ideal fruit and vegetable items that are more frequently consumed by low income children according to a study done by Drewnowski and Darmon (2005). Obesity rates are higher among low income populations and greater intake of healthy fruit and vegetables such as fresh apples, oranges, and tomatoes may aid in the solution to this problem (Hordynski et al., 2011). In home intervention that would help mothers introduce fruits and vegetables into their children's diets could help with fruit and vegetable intake in low income households (Horodynski et al., 2011). 


\section{Physical Activity}

Another detriment to children's overall health is a lack of physical activity. Children develop physical activity patterns of behavior between the time they are 3 to 5 years of age and these behaviors can influence their habits for their entire life (Hawkins \& Law, 2006; McGrady et al., 2010). From an ecological system's perspective, physical activity is considered a part of children's microsystems. Bronfenbrenner (1994) describes a person's microsystem as a pattern of their activities, which is what physical activities are for children. Children who live in poverty frequently have less resources and outlets for regular physical activity and exercise. Rose and Bodor (2015) bring up the safety of low income neighborhoods in concern with children's lack of physical activity. The authors point out that because children of impoverished families are likely to live in unsafe neighborhoods they may be discouraged from going outside and playing (Rose \& Bodor, 2015). Lack of physical activity in conjunction with the poor food access and food choices that were previously discussed can contribute to the likelihood of children becoming overweight or obese.

Instead of playing outside or engaging in other types of physical activity many children are spending their time watching television or playing video games (French et al., 2001). In fact, according to French et al., (2001) increased time watching television, playing video games, or spending time on the computer/internet is an important contributing factor to the decreased rates of physical activity in the United States. Similarly, Feng, Reed, Esperat and Uchida (2011) discuss an existing relationship between television watching and childhood obesity among low income children. Children who are watching a lot of television are most likely not getting enough exercise. The authors cite that children who watch 3 or more hours of television in one day are significantly more likely to be obese when compared to children who watched less than 1 hour of 
television a day (Feng et al., 2011). In addition to the physical activity that television watching replaces, children are also being exposed to advertisements for fast food and other unhealthy habits while watching television which could easily lead to high calorie intake and contribute to an unhealthy diet and overall poor health (Feng et al., 2011; French et al., 2011).

Physical activity can also be seen at the mesosystem of a person's ecological system. Poverty at home, neighborhood resources, and television watching practices are all factors that can viewed in a child's microsystem, influencing their immediate environments and interacting with them daily. These influences also link together to influence how much physical activity a child is engaging in. Bronfenbrenner (1994) explains that a mesosystem is simply a system of interconnected microsystems. Poverty may link with low income children's' neighborhoods to create potentially unsafe environments for them to play outdoors. Higher crime neighborhoods have been found to be associated with poverty (Rose \& Bodor, 2015) may leave these low income children with only indoor options for play, including sedentary activities, like television watching.

\section{Parental Perceptions}

The amount and types of food that young children consume at home and the amount of physical activity they participate is at least partially if not majorly dependent on their parents or caregivers. Parents opinions about which foods are healthy along with their personal experiences with certain foods is strongly related to children's' food intake (Patrick \& Nicklas, 2005).

Parents have a large amount of influence over what their children eat and how much exercise they get while at home so it is important that parents judge their children's weight correctly so that they are able to make the most healthful and beneficial choices for their children. Due to parent's perceptions of their children's weight possibly influencing their children's overall health 
through the eating and physical activity patterns the parent establishes and encourages, parental perceptions can fall within the microsystem and/or exosystem of Bronfenbrenner's ecological model. Again, according to Bronfenbrenner (1994), the exosystem is made up of environments that do not directly involve the developing children at the center of the system but influences them indirectly in the long run. Parents' opinions of their children's weight may come from exosystem environments such as the parent's own school, work, friends or family, which in turn influences the food choices and activity patterns that the parent encourages for their children, therefore, indirectly influencing the children's overall health and BMI. Additionally, parents may develop their perceptions of their child's weight and health from microsystem environments such as visits with their child to the pediatrician.

It is possible that parents may misperceive the weight of their children leaving them unaware of the changes that need to be made while also leading them to continue making unhealthy diet choices. According to research many parents do not recognize that their child is overweight or even obese (Campbell, Williams, Hampton \& Wake, 2006; Hudson, McGloin \& McConnon, 2011; Maynard et al., 2003). More specifically, in a study done by Hudson et al., (2011) more than half of parents of obese children and around $80 \%$ of parents of children who are overweight did not see a problem with their child's weight status.

There are several plausible reasons that parents may misperceive the weight of their children. Socioeconomic status is one possible reason for weight misperception. When compared to those from medium and high income backgrounds, parents of low socioeconomic statuses were more likely to misjudge their child's weight (Hudson et al., 2011). Weight problems were likely to be overlooked among children from low income homes (Hudson et al., 2011). This could be attributed to the fact that parents from disadvantaged homes are likely to be busier 
working, more stressed, and distracted than parents from higher income families (Conger, Wallace, Sun, Simons, McLoyd, \& Brody, 2002). Parents may also be in denial about the weight status or simply unknowledgeable about what is considered overweight or obese in children. Several authors note that in addition to socioeconomic status, education is one of the most important factors in correctly judging the weight of their child (Baughcum, Chamberlin, Deeks, Powers \& Whitaker, 2000; Doolen et al., 2009; Hudson et al., 2011). Because parents and caretakers have such a large amount of influence over children's diet and overall health it is important that they recognize when a child is becoming or at risk of becoming overweight or obese so that it can be addressed through appropriate prevention/intervention strategies (Hudson et al., 2011). Paired with parents being unable to identify that their child is overweight or obese, children living in urban settings who are at an increased risk for consuming larger amounts of high fat, low nutrient foods are of particular risk for weight misjudgment and the problems that follow (Drewnowski \& Darmon, 2005; Nackers \& Appelhans, 2013).

A key aspect of parent's ability to accurately perceive the weight status of family members is their involvement in the health related behaviors of their family members, such as encouragement and modeling physical activity, volunteering in sports, transporting their children to and from physical activities, providing their children with access to sports and other equipment necessary to engage in physical activity as well as a safe environment to be outdoors (Veitch, Hume, Salmon, Crawford \& Ball, 2011). Parents who do not take an active role in promoting healthful behaviors may be less likely to have the ability to correctly judge their child's weight status because of their lack of involvement and attention to this area of growth and development. As previously stated, parents have been recognized as being particularly impactful to their children's health and weight related activities such as physical activity and exercise 
(Veitch et al., 2011). More specifically, mothers believed that their encouragement was the most influential factor in whether children participated in some sort of physical activity or not (Veitch et al., 2011). Mothers can encourage their children by modeling physical activity, volunteering to be involved in organized and unorganized sports activities, and even by simply driving their children to and from sports or other physical activities (Veitch et al., 2011). The latter two suggest that mothers can be involved in and encourage physical activity even when they cannot actively participate in the activity themselves. Mothers also noted group and family activities as essential for influencing their children to be more active (Veitch et al., 2011). Lastly, dog ownership has been reported by mothers to have an impact on the frequency at which their children and the rest of the family engaged in regular walking (Veitch et al., 2011). Through parental involvement, increasing children's participation in physical activity and exercise will consequently decrease the time they spend on sedentary activities such as watching television. Unfortunately, parental involvement may be difficult for low income parents because participation in sports, owning a dog, and living in an area where it is safe for children to be active outdoors can be costly, which is a known barrier for low income families (Evans \& English, 2002). Additionally, time may be a barrier that low income parents face in regards to being involved in their child's health related behaviors. Low income parents are at an increased risk for being single parents and/or parents who work full time at several jobs during odd hours to try and financially provide basic necessities for their children such as shelter and electricity (Odgers, Caspi, Russell, Sampson, Arseneault \& Moffit, 2012). Together, money, time, and safety can serve as daily barriers to physical activity for children of low income families and barriers to parental involvement in their children's activities.

\section{Ecological System Levels and Variables of Physical Health}


The issue of childhood obesity among children living in poverty can be examined via Bronfenbrenner's ecological model through factors found to be influential on children's overall health and BMI. Each influential family background, child behavioral, and parental perception factor as earlier discusses can be examined on one or more systems of the ecological model. In the following section, an overview is provided to re-iterate the previously given information on each influential factors place on the ecological model. All of the factors fall within a system on the model that will trickle down to the developing child to impact their health and BMI. Thus, each factor bares some influence on children's health and BMI and their overall development.

At the center of the ecological model would be the impoverished child. The first topic discussed, food insecurity, would fall within the child's microsystems as food insecurity is something that the child interacts with on a daily basis in their immediate home environment as a result of living in poverty. The second topic, food access, would be a part of these child's mesosystems. Two key components of these child's microsystems, their neighborhood and their poverty at home, interact together in the mesosystem to influence food access. Poverty impacts what food shopping outlets and restaurants are available in the child's neighborhoods. What foods are nearby and available to them is going to heavily influence what foods can be accessed. Food choice as the third topic discussed would be part of the child's exosystem. Children ages three to five years of age are not making their own food choices. These children's parents are making food choices for them. Therefore, parental food choices made while purchasing food outside of the house indirectly influences the child's immediate environment.

Physical activity is another topic discussed that influences children's risk of becoming overweight or obese. Physical activity can be considered part of a child's microsystem as well as their mesosystems. Physical activity of a child, and barriers to their physical activity, occurs 
within the child's home and neighborhood environments, which are part of the microsystem. The barriers to physical activity due to poverty, and resulting lack of physical activity among these children, can also be examined by look at a child's mesosystem. Neighborhoods that may not be safe for outdoor exercise and physical activity because of high rates of crime that can occur in impoverished neighborhoods may in turn influence children to play more indoors (Rose \& Bodor, 2015); creating an interaction between the neighborhood and home environment that influences the type of physical activity low-income children participate in.

Parental perceptions is another topic that can be viewed from within the ecological model of human development. Parents' perceptions would be considered a part of impoverished children's microsystem and/or exosystem. Children are indirectly influenced by their parents' perceptions of their weight status which is based on parents' education and knowledge about early child physical health. This information can be gained from environments within the exosystem such as the parent's own schooling, friends, family, and/or work while the child is not present; as well as from environments such as the child's pediatrician's office which they directly participate in. How parents perceive their children's weight is going to influence the food choices they are making for their children and how much physical activity they are encouraging their children to engage in. Further, these food choices and physical activity patterns as established and encouraged by parents are going to influence children's overall health and BMI.

Lastly, two variables that come up considerably in the literature review are parental income and education. Both of these variables are also considered part of children's exosystems. Both parental income and education are going to influence choices that parents are making on behalf of their children and in turn indirectly influence the child. Affordability is going to 
influence food and other health related choices parents are making for their children which are dependent on their income. Parent education is also going to impact the developing child indirectly because it impacts the amount of knowledge that parents have about making healthful choices for their families. The developing child does not actively take part in making these decisions, but the decisions that parents are making based on their income and education are going to impact the child's health and BMI.

\section{Gaps in the Literature}

A majority of research on childhood obesity among children living in poverty focuses on older children and early adolescents (Di Noia \& Byrd-Bredbenner, 2014; Feng et al., 2011; Grutzmacher \& Gross, 2011; Hudson et al., 2011; Nackers \& Appelhans, 2013; Pinard, Hart, Hodgkins, Serrano, McFerren \& Estabrooks, 2012). It would be beneficial to this area of research if more studies were conducted examining the issue among younger children from the preschool age to around 7 years of age. Information on childhood obesity among low income children of this particular age group would be valuable because prevention and intervention efforts are most effective and beneficial when targeted at younger populations (Horodynkski et al, 2011). It is important to note that some researchers do encompass this age group by including children from a broad range of ages in their studies; however, it would still prove to benefit the body of literature if more researchers focused solely on children among these younger ages to investigate the unique factors influencing young low-income children's physical health.

Another noteworthy gap that lies within this body of literatures is that parental perceptions of child's weight is not examined in conjunction with parental health and weight related behaviors, such as food and mealtime practices and permission of sedentary activities such as television watching. This is an important gap to fill because low income populations are 
already at an increased risk of consuming more fast food due to living in an area with high fast food density (Drewnowski \& Darmon, 2005). They are also already face barriers in regards to engaging in physical activity including neighborhood safety and resources needed to exercise, which may lead them to engage in more sedentary behaviors such as watching television (Rose \& Bodor, 2015). It is also crucial to recognize this gap because children ages 3-5 are not making health and weight related decisions for themselves. Their parents are purchasing their food and allowing or making rules regarding television viewing for their children. Therefore, it would be beneficial to the body of research if parents' perceptions of their child's weight were examined alongside the health and weight related decisions parents are making for their children.

\section{Current Study}

Based on the previous literature, several family background factors, child behavioral factors, and parental perceptions and behaviors were examined in relation to low-come children's Body Mass Index (BMI), which captures percentage of body fat by taking a child's weight in kilograms and dividing it by their height in meters (Center for Disease Control and Prevention, 2015). Prior research has identified family background factors including income and education to be important contributions to children's BMI through barriers to healthy produce and fresh meal preparation and storage at home (Appelhans et al., 2014; Baughcum, Chamberlin, Deeks, Powers \& Whitaker, 2000; Doolen et al., 2009; French et al., 2001; Grutzmacher \& Gross, 2011; Hudson et al., 2011). It was hypothesized in the current study that: (a) child BMI would be higher among the lowest income group compared to higher income families, and that (b) child BMI would be higher among children with parents who had the lowest educational attainment compared to those whose parents had greater education. Family income and education are important factors to look at when examining young children's BMI because very few studies 
have examined these factors for children 3 to 5 years of age; therefore the current study aims to help fill this important gap in the literature.

Previous literature has also shown that child behavioral factors, such as television viewing and fast food consumption, also have important influences on children's BMI (Drewnowski \& Darmon, 2005; Feng et al., 2011; French et al., 2001; Nackers \& Appelhans, 2013; Salois, 2011). It was hypothesized that: (a) child BMI would higher among children who eat fast food more frequently in a week compared to children who eat fast food less frequently in a week and that (b) child BMI would be higher among children who watch more TV in a week compared to children who watch less TV in a week. When children are watching television they are not being physically active, as such, the number of hours of television watched is an inverse measure of physical activity that allows for the examination of number of known hours of sedentary behavior per week (French et al., 2001). Again, this is an important contribution to the literature because very few studies have been conducted on BMI in children ages 3-5.

Parental perceptions and their behaviors have also been recognized as important factors in children's BMI (Campbell, Williams, Hampton \& Wake, 2006; Hudson, McGloin \& McConnon, 2011; Maynard et al., 2003; Veitch et al., 2011). It was hypothesized that: (a) child BMI would be the same regardless of parents' rating of their child as underweight, average weight, or overweight because of previous literature reporting that parents are commonly inaccurate in their perceptions of their children's weight (Doolen et al., 2009; Hudson et al., 2011; Maynard et al., 2003). It was also hypothesized that: (b) the number of days in a week that the child ate fast food would be the same regardless of parents rating of their child as underweight, average weight, or overweight and lastly that (c) the number of days in a week that 
the child watched TV for more than 1 hour will be the same regardless of parents rating of their child as underweight, average weight, or overweight. 


\section{Chapter III: Method}

\section{Participants}

The state of Florida funded a project entitled the Miami-Dade School Readiness Project (MDSRP; Winsler, Tran, Hartman, Madigan, Manfra \& Bleiker, 2008). The purpose of this project was to examine children's physical development among families who qualified for childcare state subsidies and whom qualified for, but were not enrolled in, Head Start programs. For the current study, data from this existing dataset was used to investigate how various background and behavioral variables can influence young children's BMI. Of the 3,838 preschool age children and mothers in the original study, 681 were randomly selected to complete a health questionnaire. 581 of the participating mothers reported child BMI information and made up the final sample. A majority of the participants (58\%) were Hispanic/Latino with $33 \%$ of the sample Black/African American children and the remaining (9\%) were White or other (Winsler et al., 2008). A majority of the parents who participated in the study were also single mothers.

\section{Procedures}

Child Development Services (CDS) from the Miami-Dade County recruited families who qualified for state subsidies for childcare. The CDS agency personnel collected consent from interested families upon enrollment in the childcare centers. The families were asked whether they wanted to participate in the project and it had no impact on their experience in the childcare setting. Choice to participate in the project or not had no impact or consequence on their eligibility for the child care subsidies. From the families who agreed to participate, a random sample was selected to receive a health questionnaire developed and administered by the Florida Supporting Partnerships to Assure Ready Kids (SPARK) of Miami-Dade County. 


\section{Measures}

Child BMI. Child age, weight, and height were gathered from the health questionnaire. This data was used to calculate child BMI using the U.S. Department of Health and Human Services chart for calculating Body Mass Index (Center for Disease Control and Prevention, 2015). BMI was used as a continuous variable.

Parent income. All participants were considered to be low income. They had family incomes below $150 \%$ of the federal poverty line, which is required to qualify for childcare subsidies (Winsler et al., 2008). Parent income was gathered through the health questionnaire. Parents were asked, "What is your family's monthly income?" with six response categories: less than $\$ 1,900 ; \$ 1,991-\$ 2,500 ; \$ 2,501-\$ 3,000 ; \$ 3,001-\$ 3,500 ; \$ 3,501-\$ 4,040$; and $\$ 4,041$ and greater. The variable was examined and recoded into three categories based on cell size: less than $\$ 1,900, \$ 1,991-\$ 2,500$, and $\$ 2,501$ and greater.

Parent education. Parent education was collected through the health questionnaire. Parents were asked, "Which of the following best describes your education?" This variable was already coded categorically, but due to cell size several categories were combined. The final categories included: completed schooling up to $6^{\text {th }}$ grade, completed schooling up to $9^{\text {th }}$ grade, completed some high school, completed high school, completed some technical training, and completed at least some college.

Fast food consumption. The amount of fast food children consumed was gathered via the health questionnaire. Parents were asked, "In the past 7 days, how many days did your child eat fast food such as McDonalds or KFC?" Due to cell size this information was recoded as the following categories: 0 days in the past 7 days, 1 day in the past 7 days, 2 days in the past 7 days, 3 days in the past 7 days, and 4 or more days in the past 7 days. 
Amount of television watched. The amount of television children watched in a week's time was assessed via the health questionnaire. The parents were asked, "In the past 7 days, how many days did your child watch more than 1 hour of television or videos?" Due to cell size and distribution this data was examined continuously and categorically. The categories included 7 days and less than 7 days.

Parent rating of child's weight. Parent's rating of their child's weight was gathered through the health questionnaire. The parents were asked, "Do you consider your child to be underweight, normal weight, or overweight?" and asked to rate their child using a 10-point scale. Due to cell size and phrasing of this question item, this variable was coded categorically with the categories being: underweight, average weight, and overweight.

\section{Data Analyses}

Family background factors. The study hypothesis that parental income would be linked with child BMI was examined using an ANOVA. Specifically, it was hypothesized that lower parental income would be linked to higher child BMI. The hypothesis that parental education would be linked with child BMI was also examined using an ANOVA. Specifically, it was hypothesized that parents with lower levels of education would have children with higher BMI's compared to the children of parents with greater levels of education. Post hoc comparisons using $t$ tests with the Bonferroni correction were utilized in all ANOVAs for group mean comparisons.

Child behavioral factors. The study hypothesis that child BMI would be linked to the number of times that the child ate fast food in a week's time was examined using an ANOVA. Specifically, it was hypothesized that higher child BMI would be linked with a greater number of times that the child ate fast food in a week's time. Because the variable TV watching was coded continuously and categorically (7 days and less than 7 days) a correlation and an ANOVA were 
run to test the hypothesis that child BMI would be related to the number of days in a week that the child watched television for more than 1 hour. Specifically, it was hypothesized that children with higher BMIs parents would report them watching more TV than children with lower BMIs.

Parent perceptions and child behaviors. An examination of the study null hypothesis that parents' rating of their child's weight as underweight, average weight, or overweight would not be linked to child BMI was examined using an ANOVA. The study hypothesis that there would not be a difference between parents' rating of their child's weight and the number of times their child was given and consumed fast food in a week's time (1 day, 2 days, 3 days, or 4 and more days) was examined using a chi-square analysis. Similarly, a chi-square analysis was also used to examine the hypothesis suggesting that no differences would be found between parents' rating of their child's weight (underweight, average, or overweight) and number of days in a week's time (7 days or less than 7 days) that the child watched television for more than 1 hour. Specifically, it was hypothesized that regardless of parents rating of their child's weight, children's TV viewing would not be different. An ANOVA was run to test the hypothesized relationship between parental rating of their child's weight and the continuous number of days in a week that the child watched TV for at least 1 hour. 


\section{Chapter IV: Results}

\section{Descriptive Statistics}

Descriptive statistics for each variable within family background factors, child behavioral factors, and parental perceptions were examined (see Table 1). The average child BMI was 17.19 $(S D=3.00)$. This average fell within the $50^{\text {th }}$ percentile on the Body Mass Index-for-age percentiles chart provided by the Center for Disease Control (2000). There was great variability within the range of recorded child BMIs with the lowest BMI at 10.26 , falling below the $5^{\text {th }}$ percentile on the Center for Disease Control BMI for age chart (2000) and the highest being 38.08 , falling above the $95^{\text {th }}$ percentile on the chart. The majority of parents $(64.3 \%)$ fell within the lowest income category of less than $\$ 1,900$ a monthly of family income. In regards to parental education, the largest percentage of participants $(40.9 \%)$ fell within the category of completed high school by either graduating or obtaining a GED.

Regarding child behavioral factors, the largest minority of parents (33.4\%) reported that their child consumed fast food 1 day out of the past 7 days. The next largest group of parents (29.2\%) reported that their child consumed fast food 2 days out of the past 7 . Regarding TV viewing, the largest percentage of participants (60.4\%) fell within the category of less than 7 days a week of one hour or more of TV viewing versus the category of 7 days a week. The average number of days in the past week that participating children watched TV for more than an hour was $1.39(S D=.49)$. Lastly, in regards to parents' perceptions of their children's weight, the largest percentage of participants (69.8\%) rated their children as being of average weight.

\section{Family Background Factors}


In regards to family background factor, there was no significant difference in children's BMI based on monthly parental income, $F(2,395)=1.04, p>.05$. Similarly, parental education was not linked with child BMI, $F(5,432)=1.26, p>.05$.

\section{Child Behavioral Factors}

There was no significant difference in the number of times children ate fast food in a week's time and their BMI, $F(4,412)=3.208, p>.05$. Correlation analysis examining child BMI and number of days in a week that the child watched TV for 1 hour or more revealed a positive significant relationship, $r(415)=.083, p<.05$. Watching more TV per week was associated with a greater BMI score, while less hours of TV viewing was associated with lower BMIs. Interestingly, there was no significant difference in child BMI and TV viewing when examined using an ANOVA to compare BMI of children who watch TV for more than 1 hour every day each week versus children who watched TV for 1 hour or more less than 7 days a week, $F(1,415)$ $=2.44, p>.05$.

\section{Parental Perceptions}

Children's BMI was significantly different by all three parents' ratings of their children's weight with underweight, average weight, and overweight groups all significantly different from each other, $F(2,415)=22.94, p<.05$. Children who were rated as overweight by their parents had significantly higher BMIs on average $(M=17.68, S D=1.46)$ than those rated as average weight $(M=16.57, S D=1.45)$ or underweight $(M=15.79, S D=1.37)$. Similarly, the means for those rated as average weight was significantly higher than that of children rated as underweight by their parents. No relationship was found between parents' rating of their children's weight 
and the number of times in a week that their children consumed fast food in a week's time, which was categorized as $0,1,2,3$, or 4 or more days, $X^{2}(8)=6.942, p>.05$.

There was a significant difference in the parents' rating of their child's weight and the number of days in a week that their child watched TV for more than 1 hour, with TV viewing categorized as 7 days and less than 7 days, $X^{2}(2)=6.53, p<.05$. Children who were rated by their parents as underweight reportedly watched less TV than was expected based on previous research while those rated as overweight watched more TV than expected. For children rated as underweight by their parents, $69.8 \%$ watched TV for less than 7 days a week while only $30.2 \%$ of these children watched TV for all 7 days a week. Of the children who were rated as being of average weight, $59.4 \%$ watched TV for less than 7 days a week while $40.6 \%$ of these children watched for all 7 days a week. For children rated as overweight, $49.1 \%$ of children watched TV for less than 7 days a week with $50.9 \%$ of these children watched for 7 days. Interestingly, there was no significant difference found between parental rating of their children's weight and the continuous number of days in a week's time that their child watched TV for more than 1 hour per day, $F(2,481)=2.02, p>.05$. 


\section{Chapter V: Discussion}

The aim of the current study was to investigate the relationship between several different factors and impoverished children's physical health, specifically their BMI. Bronfenbrenner's Ecological model was used as a framework for examining family background factors such as parental income and education, child behavioral factors including fast food consumption and TV watching, and parental perceptions of their children's weight and how these factors may be related to children's' BMI. A majority of the participants in the current study fell within the lowest category of monthly income indicating that they lived well below the poverty line. This implies that while all participants were considered to be low income and fell below the poverty line that most of our participants were more drastically impoverished than was originally realized. A majority of participants fell within the same category of education level as well, completing high school, receiving a GED, or completing some technical training. The second largest group reported completing some high school while very few participants reported receiving any amount of college education.

Interesting trends were seen in the amount of fast food that parents were allowing their children to eat along with the amount of TV their children were watching. A majority of parents allowed their children to consume less fast food than expected based on previous research ( 1 and 2 days per week) and to watch less TV than expected based on previous research with lowincome populations (Drewnowski \& Darmon, 2005; French, 2011; Salois, 2011). More than half of participants reported allowing their children to watch more than 1 hour of TV for less than 7 days per week. The current study investigated children of younger ages than were studied in previous research, which could explain why findings were different than in past literature.

\section{Family Background Factors}


The study hypotheses that the family background factors of parental income and education would be related to children's BMI were not supported. No significant differences were found in children's BMI based on either family background factors. Based on previous research that income and education are highly influential agents on family's health and health related behaviors such as food shopping, reading nutrition labels, and correctly perceiving weight status, it was hypothesized that low levels of both income and education would be linked with higher BMI (Baughcum et al., 2000; Doolen, Alpert \& Miller, 2009; Drewnowski \& Darmon, 2005; French, Story \& Jeffery, 2001; Hudson, McGloin \& McConnon, 2011; Nackers \& Appelhans, 2013). The limited variance in participants' reports of both income and education could partially explain why no significance was found in the current study. For example, all participants were considered to be low income but the majority of participants fell in the lowest income category reportedly earning less than $\$ 1,900$ a month. Similarly, a majority of participants (40\%) fell within the same category of education, reportedly finishing high school or receiving a GED. Three out of the other 5 categories for education each had less than $10 \%$ of participants fall into them and each of the last 2 categories had less than $20 \%$ of participants.

Previous research reporting significance between income and BMI and education and BMI likely had more variability (e.g. Nackers \& Appelhans, 2013). It is also possible that because a majority of parents reported such low monthly incomes that they are able to purchase healthier, more costly food items with the help of governmental food assistance programs, lessening the likelihood of their children consuming high fat energy dense foods and having higher BMIs (Grutzmacher \& Gross, 2011; Nackers \& Appelhans, 2013). When variability exists in parental income, qualification for food assistance programs also varies. Qualification for food assistance programs requires that families annual household income fall below a specific dollar 
amount. Families reporting higher incomes, though still living in low-income neighborhoods, may be cut off from when they start earning only a small dollar amount more per year (United States Department of Agriculture Food and Nutrition Service, 2016); in turn, limiting their availability to healthier food options. The majority of participants in the current sample were of the lowest income category making \$1900 a month or less, meaning that they would receive governmental food assistance. This assistance would give them greater access to and allow them to purchase higher priced food items, such as fresh fruits and vegetables. Governmental food assistance programs give families the opportunity to purchase healthier food items as shown in previous literature reporting that about $19.6 \%$ of food purchased by recipients of food assistance programs were fruits and vegetables (Grutzmacher \& Gross, 2011; Nackers \& Appelhans, 2013). As previously described, parental income, as a part of Bronfenbrenner's exosystem, can indirectly influence children's health and development through restricting the food choices that parents are making for their children. Participation in governmental food assistance programs, however, can make income less likely to influence children in the exosystem in a negative way because lower income parents can use their assistance to make more healthful food purchases.

\section{Child Behavioral Factors}

No significant difference was found between numbers of days that children ate fast food and their BMI. It was hypothesized that children who ate fast food for more days in a week would have higher BMIs. Research shows that fast food restaurants densely populate low income neighborhoods and that meals at a fast food restaurant are often cheaper than home cooked meals. The same research also shows that greater consumption of fast food is liked to higher BMI and risk of obesity (Drenowski \& Darmon, 2005; Salois, 2011). The lack of significance could be attributed to fact that a majority of participants reported a low number of days that fast 
food was consumed. Overall, lower rates of fast food consumption were reported than expected based on previous literature (e.g. Drewnowski and Darmon, 2005) with a majority reportedly only consuming fast food 1 or 2 days a week. This is different than previous research stating that low income families consume more fast food than families from other socioeconomic backgrounds (Drewnowski \& Darmon, 2005; Nackers \& Appelhans, 2013; Salois, 2011). A possible contribution to this difference could be the age of the participants in the current study. This study focused on children ages 3-5 while previous research tended to focus on older children. Additionally, the location that the study was conducted in could account for differences in the current study compared to past research. Participants were from Miami Dade County, Florida where more than half of the population (66.2\%) is of Hispanic or Latino decent (United States Census Bureau, 2015). The emphasized importance placed on extended family in Hispanic culture may indicate that the families in the current sample may be consuming more home cooked meals at other family member's homes than participants from other cultures (Skala, Chuang, Evans, Hedberg, Dave, \& Sharma, 2012). Thereby, the Hispanic participants in the current study may have had additional resources in the form shared extended family meals, as well as shared food costs, making them less likely to consume fast food.

Child BMI was positively correlated with number of days in a week that children watched TV for 1 hour or more. Specifically, watching more TV per week was associated with having a higher BMI, while watching less was associated with lower child BMI. This suggests that children who are sedentary for long period of time are likely to have higher BMIs. Previous research with adults shows a similar pattern with engagement in more sedentary activities relating to the likelihood of having a higher BMI (Owen, Bauman, \& Brown, 2009). Research reveals that a lack of safe outlets for outdoor physical activity in low income neighborhoods may 
lead children living in these areas to engage in more sedentary activities, like watching TV (Rose \& Bodor, 2015). Bronfenbrenner's Ecological model shows the possibility of one segment of a child's microsystem influencing another, also referred to as the mesosystem, which is demonstrated in this finding. Bronfenbrenner's explains the mesosystem as a system of interactions between different parts of the microsystem (1994). In this particular finding, one microsystem, a child's neighborhood, may influence events occurring in another microsystem, their home. The lack of outlets for safe outdoor play in these low income neighborhoods likely influenced these children to watch greater amounts of TV as an alternative activity (e.g. Rose \& Bodor, 2015). The interaction between these two environments in the mesosystem can influence a child's overall health and development by making them less likely to be physically active and more likely to engage in sedentary activities, which is associated with having a higher BMI.

The finding that watching more TV in a week was associated with having a higher BMI is important to focus on because intervention strategies for childhood obesity commonly begin with improving on diet quality as opposed to physical activity (e.g. Hordynkski et al. 2011). This finding highlights the influence that sedentary behaviors, such as TV watching, may have on children's BMI and that sedentary behavior may be just as impactful as diet on children's health and weight. Future intervention strategies aimed at reducing rates of childhood obesity may need to better emphasize the importance of eliminating sedentary activity and promoting physical activity and exercise in addition to simply improving on diet quality.

\section{Parental Perceptions}

The study hypothesis that children's BMI would be the same regardless of their parents rating of their weight was not supported. Children's BMI differed significantly by parental ratings of their children's weight as underweight, average weight, or overweight. Previous 
research shows that parents are commonly incorrect in their perceptions of their children's weight (Doolen et al., 2009; Hudson et al., 2011; Maynard et al., 2003), which is why it was hypothesized that BMI would not differ according to rating. This finding shows that the parents in this study were correct in perceiving their children's weight status, which is an important contribution as previous research has shown low income parents to be typically inaccurate in their ratings of their children's weight (Hudson et al., 2012; Maynard et al., 2003). This finding is new to this field of study and is an important contribution because it highlights different findings among different population, with the current study involving families living in the lowest income brackets; as well as primarily of Latino decent.

Additionally, the current study findings raise questions about why parents are allowing their children to engage in unhealthy behaviors regardless of their weight status. For example, it is important to note that despite parents in the current study recognizing that their children were overweight, they still allowed them to watch more TV than children who were rated correctly as average weight or underweight. In previous research, the incorrect weight perceptions by parents have been noted as a possible reason why low income children were engaging in unhealthy behaviors (Hudson et al., 2011). Finding low income parents who are correct in their perceptions of their children's weight but still allowing them to engage in unhealthy behaviors that can negatively impact their physical health highlights the need to examine parents' understanding of the harmfulness of sedentary behavior. This direction of research is important because it allows for examination into whether those parental perceptions actually impact their children's health related behaviors, as regardless of accuracy, these children are engaging in unhealthy behaviors, such as more TV watching. It also raises the question of what can be done to educate parents on 
the harmfulness of sedentary behavior in order to reduce children's likelihood of watching greater amounts of TV and engaging in other sedentary activities at higher rates.

There was no significant difference found between parents rating of their children's weight and the number of days in a week that the children consumed fast food, supporting the study hypothesis. In regards to parents rating of their children's weight and the number of days in a week that children watched an hour or more of TV, there was a significant difference when the variable was coded categorically as 7 days a week and less than 7 days a week. This does not support the study hypothesis that the number of days the children watched TV for more than an hour per day in a week would not be different by parents' ratings of their weight. It shows that TV viewing 7 days a week by children was more likely to occur among children whose parents rated them as being overweight. It is interesting to note that the findings for TV watching in children matched up with the parents rating of their children's weight. Parents who rated their children as being overweight were allowing their children to watch TV for more days than parents who rated their children of average weight and as underweight. When the variable was coded continuously as 1-7 days a week, there was no significant difference found between amount of TV watched and parents rating of children's weight. A possible explanation for the lack of significance when TV was coded continuously could be the lack of variance in the reports of TV watching. The largest portion of participants, 253, reported allowing their children to watch TV for more than 1 hour per day for all 7 days in a week. Small amounts of participants reported allowing their children to only watch TV for 0-6 days. For example, only 37 participants allowed their children to watch for more than an hour for 1 day and only 44 allowed their children to watch for 4 days. 
The two variables within these findings can be viewed within the microsystem and exosystem on Bronfenbrenner's Ecological model. Children directly engage in TV watching, typically as a frequent hobby or activity for themselves in the home environment, which makes TV watching a part of a child's microsystem. Engagement in sedentary activities can lead to higher BMI, thus how much TV a child watches in their microsystem can produce varying health outcomes. Parental perceptions and knowledge about child physical health regarding BMIs are a part of children's exosystems and can impact their health outcomes indirectly through the food choices and physical activity behaviors the parents are making based on their perceptions of their children's weight.

\section{Limitations and Future Directions}

There were some noteworthy gaps found within the literature on childhood obesity among children living in poverty and their associations with activity level, food choices, and parental perceptions. One gap in the research is that a majority of the studies that examined childhood obesity among children living in poverty focused solely on those residing in urban areas. In fact, only one study conducted by Berlin, Lambert and DeLamatre (2013) addressed childhood obesity in a rural setting. This is a gap that would be beneficial to close because according to the authors more than one third of the rural Appalachian children who were included in their study were considered to be overweight or obese and these are children who are benefitting from the awareness that research brings to the subject (Berlin et al., 2013).

Another important gap was noted in the samples of children that research regarding weight focuses on. When examining problems related to being underweight or malnourished research tends to focus on low income populations, but when examining contrasting problems related to being overweight or obese research focuses on just the general population. Obesity is 
viewed as an overeating problem associated with individuals who have access to many resources while under nutrition is presented in a way that links this problem with low income individuals. This is a critical gap because overweight or obese individuals may suffer their weight problems due to a lack of resources they have from being low income, as well. They have less nutritious food options and may be undernourished, as well, but it simply does not show because they are only eating the unhealthy food available to them.

In addition to gaps found within the literature, there were some limitations to the current study worth noting. First, data was self-reported via questionnaire by participants. This leaves room for biased or false reporting. Future researchers should include observational data of health related behaviors parents and children participate in. A second limitation to the current study is that the data was correlational so causation could not be implied. Future research should implement longitudinal and/or quasi-experimental designs to better investigate casual relationships between parental perceptions, health related behaviors they allow or promote for their children, and their children's physical health.

\section{Conclusions}

Childhood obesity among impoverished preschool age children is a topic of research that is unfortunately underrepresented within the existing body of literature (Larson et al., 2011). Previous research has noted the impact that food choices, physical activity, and parental perceptions can have on children's health and BMI (e.g. Hudson et al., 2011). The current study added to this literature by examining an especially vulnerable population of impoverished 3-5 year old children. The findings in the current study were supported by Bronfenbrenner's ecological model showing that children's health and developmental outcomes can be influenced by factors within every system of the model, despite how immediate or direct they are in a 
child's environment. The current study demonstrates that factors that children interact with closely and on a daily basis, such as their neighborhood, as well as factors that they do not directly interact with, such as their parent's income, can influence their developmental health and BMI outcomes, similarly.

The current study suggest the negative potential consequences that sedentary behaviors and an overall lack of physical activity can have on children's BMI in the finding showing that children who watched more TV also had higher BMIs. The current study also provided implications for parents' recognition and understanding of their children's health and BMI and the behaviors they are allowing or promoting in the home. Parents in the current study were accurate in their perceptions of their child's BMI as overweight but were still allowing them to watch more TV when compared to other children. This implies that in households with children with lower BMIs, rules for TV allowances and restrictions may be harsher and conversely these rules may be more lenient in households with children with higher BMIs. In the current study, parents who accurately rated their children as overweight but also had less strict regulations on TV watching may either have been content with their children's overweight status or unaware of how influential sedentary behaviors, such as watching TV, are on their child's BMI. This highlights the need to examine parents' understanding of the harmfulness of sedentary behavior as well as the need for educational interventions. Bronfenbrenner's model shows that events in one microsystem can influence occurrences in another. The lack of parental knowledge of the harmfulness of sedentary behavior in the home may interact with the unsafe neighborhood conditions found in low income areas (Rose \& Bodor, 2015) resulting in greater time spent watching TV. 
The current study is important because it opens a conversation about the need for exploring further into the topic of childhood obesity. The study raises questions about examining further relationships between sedentary behaviors and childhood obesity and the need for more research among younger age groups than previously studied. It also brings up the question of whether more education is needed for parents in this population. Past research has focused on whether education is needed to help parents better identify weight problems among their children (Hudson et al., 2011; Veitch et al., 2011). The current study showed that parents could identify children's weight problems but were still allowing them to engage in unhealthy, sedentary behaviors. This suggests that education is still needed, but in way that teaches parents about the risks associated with decreased physical activity and exercise among young children. 


\section{References}

Appelhans, B., Waring, M., Schneider, K., \& Pagoto, S. (2014). Food preparation supplies predict children's family meal and home-prepared dinner consumption in low-income households. Appetite, 76, 1-8.

Baughcum, A., Chamberlin, L., Deeks, C., Powers, S., \& Whitaker, R. (2000). Maternal perceptions of overweight preschool children. Pediatrics, 106, 1380-1386.

Berlin, K., Hamel-Lambert, J., \& DeLamatre, C. (2013). Obesity and overweight status health disparities among low-income rural Appalachian preschool children. Children's Health Care, 42, 15-26.

Bronfenbrenner, U. (1994). Ecological models of human development. International Enclyclopedia of Education, 3, 37-43.

Campbell, M., Williams, J., Hampton, A., \& Wake, M. (2006). Maternal concern and percpetions of overweight in Australian preschool-aged children. Medicine and the Community, 184, 274-277.

Centers for Disease Control and Prevention. (2014, September 3). Retrieved April 5, 2016, from http://www.cdc.gov/obesity/data/childhood.html

Collings, P.J., Brage S., Ridway C.L., Harvey N.C., Godfrey K.M., Inskip H., Cooper C., Wareham N.J., \& Ekelund U. (2013) Physical activity, intensity, sedentary time, and body composition in preschoolers. American Journal of Clinical Nutrition, 97, 1020-028.

Conger, R. D., Wallace, L. E., Sun, Y., Simons, R. L., McLoyd, V. C., \& Brody, G. H. (2002). Economic pressure in African American families: A replication and extension of the family stress model. Developmental Psychology, 38,179-193. 
DiNoia, J. (2014). Determinants of fruit and vegetable intake in low-income children and adolescents. Nutrition Reviews, 72, 575-590.

Doolen, J., Alpert, P., \& Miller, S. (2009). Parental disconnect between perceived and actual weight status of children: A metasynthesis of the current research. Journal of the American Academy of Nurse Practitioners, 21, 160-166.

Drewnowski, A., \& Darmon, N. (2005). Food choices and diet costs: An economic analysis. American Society for Nutritional Sciences, 135, 900-904.

Duncan, G., Brooks-Gunn, J., \& Klebanov, P. (1994). Economic deprivation and early childhood development. Child Development, 65, 296-318.

Evans, G., \& English, K. (2002). The environment of poverty: Multiple stressor exposure, psychophysiological stress, and socioemotional adjustment. Child Development, 73, 1238-1248.

Feng, D., Reed, D., Esperat, C., \& Uchida, M. (2011). Effects of TV in the bedroom on young hispanic children. American Journal of Health Promotion, 25, 310-318.

French, S., Story, M., \& Jeffery, R. (2001). Environmental influences on eating and physical activity. Public Health, 22, 309-335.

Grutzmacher, S., \& Gross, S. (2011). Household food security and fruit and vegetable intake among low-income fourth graders. Journal of Nutrition Education Behavior, 43, 455463.

Hawkins, S., \& Law, C. (2006). A review of risk factors for overweight in preschool children: A policy perspective. International Journal of Pediatric Obesity, 1, 195-209. 
Horodynski, M., Baker, S., Coleman, G., Auld, G., \& Lindau, J. (2011). The healthy toddlers trial protocol: An intervention to reduce risk factors for childhood obesity in economically and educationally disadvantaged populations. BMC Public Health, 11, 1-7.

Huang, J., Becerra, K., Oda, T., Walker, E., Xu, R., Donohue, M., ... Breslow, A. (2007). Parental ability to discriminate the weight status of children: Results of a study. Pediatrics, 120, 112-119.

Hudson, E., McGloin, A., \& McConnon, A. (2011). Parental weight (mis)perceptions: Factors influencing parents' ability to correctly categorise their child's weight status. Matern Child Health, 16, 1801-1809.

Larson, N., Story, M., \& Nelson, M. (2009). Neighborhood environments: Disparities in access to healthy foods in the U.S. American Journal of Preventive Medicine, 36, 74-81.

Markant, J. C., \& Thomas, K. M. (n.d.). Retrieved April 5, 2016, from http://www.oxfordhandbooks.com/view/10.1093/oxfordhb/9780199958450.001.0001/oxf ordhb-9780199958450-e-6\#oxfordhb-9780199958450-div1-43

Maynard, L., Galuska, D., \& Serdula, M. (2003). Maternal perceptions of weight status of children. Pediatrics, 111, 1226-1231.

McGrady, M., Mitchell, M., Theodore, S., Sersion, B., \& Holtzapple, E. (2010). Preschool participation and BMI at kindergarten entry: The case for early behavioral intervention. Journal of Obesity, 2010, 1-6.

McLoyd, V. (1990). The impact of economic hardship on black families and children: Psychological distress, parenting, and socioemotional development. Child Development, $61,311-346$. 
McLoyd, V. (1998). Socioeconomic disadvantage and child development. American Psychologist, 53, 185-204.

Metallinos-Katsaras, E., Must, A., \& Gorman, K. (2012). A longitudinal study of food insecurity on obesity in preschool children. Journal of the Academy of Nutrition and Dietetics, 112, 1949-1958.

Nackers, L., \& Appelhans, B. (2013). Food insecurity is linked to a food environment promoting obesity in households with children. Journal of Nutrition Education Behavior, 45, 780784.

Odgers, C. L., Caspi, A., Russell, M. A., Sampson, R. J., Arsenault, L., \& Moffitt, T. E. (2013). Supportive parenting mediates widening neighborhood socioeconomic disparities in children's antisocial behavior from ages 5 to 12. Developmental Psychopathology, 24, 705-721. Retrieved April 5, 2016.

Owen, N., Bauman, A., \& Brown, W. (2009). Too much sitting: a novel and important predictor of chronic disease risk? British Journal of Sports Medicine, 43, 81-83.

Patrick, H., \& Nicklas, T. (2005). A review of family and social determinants of children's eating patterns and diet quality. Journal of the American College of Nutrition, 24, 83-92.

Pinard, C., Hart, M., Hodgkins, Y., Serrano, E., McFerren, M., \& Estabrooks, P. (2012). Smart choices for healthy families: A pilot study for the treatment of childhood obesity in low income families. Health Education \& Behavior, 39, 433-445.

Rose, D., \& Bodor, N. (2006). Household food insecurity and overweight status in young school children: Results from the early childhood longitudinal study. Pediatrics, 117, 464-473.

Salois, M. (2012). The built in environment and obesity among low-income preschool children. Health \& Place, 18, 520-527. 
Shaw, P., Greenstein, D., Lerch, J., Clasen, L., Lenroot, R., Gogtay, N., ... Giedd, J. (2006). Intellectual ability and cortical development in children and adolescents. Nature, 440, 676-679.

Smoyer-Tomic, K., Spence, J., Raine, K., Amrhein, C., Cameron, N., Yasenovskiy, V., ... Healy, J. (2008). The association between neighborhood socioeconomic status and exposure to supermarkets and fast food outlets. Health \& Place, 14, 740-754.

U.S. Census Bureau. (2008). American community survey. Retrieved from http://ww w.mchb.hrsa.gov/chusa10/popchar/pages/105ruc.html

United States Department of Agriculture Food and Nutrition Service. (2016, January 29). Retrieved April 5, 2016, from http://www.fns.usda.gov/wic/who-gets-wic-and-how-apply

Veitch, J., Hume, C., Salmon, J., Crawford, D., \& Ball, K. (2011). What helps children to be more active and less sedentary? Perceptions of mothers living in disadvantaged neighbourhoods. Child: Care, Health and Development, 39, 94-102.

Winsler, A., Tran, H., Hartman, S., Madigan, A., Manfra, L., \& Bleiker, C. (2008). School readiness gains made by ethnically diverse children in poverty attending center-based childcare and public school pre-kindergarten programs. Early Childhood Research Quarterly, 23, 314-329. 
Table 1

Continuous and Categorical Comparisons to BMI

\begin{tabular}{lllllc}
\hline & $M(S D)$ & $\%$ & Median & Mode & Range \\
\hline BMI & $17.19(3.00)$ & & 16.63 & 16.55 & $10-38$
\end{tabular}

Parent Education

Up to $6^{\text {th }}$ grade

$17.6 \%$

Up to $9^{\text {th }}$ grade

$8.6 \%$

Some high school

$18.8 \%$

Completed high school

$40.9 \%$

Some technical training

$7.1 \%$

Some college

$7.1 \%$

Parent Monthly Income

Less than $\$ 1900$

$64.3 \%$

$\$ 1991-\$ 2500$

$17.2 \%$

$\$ 2501+$

$18.5 \%$

Fast Food Consumption

1 in last 7 days $\quad 33.4 \%$

2 in last 7 days $\quad 29.2 \%$

3 in last 7 days $\quad 9.5 \%$

$4+$ in last 7 days $\quad 5.6 \%$

TV Viewing

$1.40(0.49) *$
1

1

$1-7$

$1+$ hour every day

$39.6 \%$

$1+$ hour, not every day

$60.4 \%$ 


\begin{tabular}{ccc}
\hline Parent Perceptions & & \\
Underweight & $15.79(1.37)^{*}$ & $19.7 \%$ \\
Average weight & $16.57(1.45)^{*}$ & $69.8 \%$ \\
Overweight & $17.68(1.46)^{*}$ & $10.5 \%$ \\
\hline
\end{tabular}

Note. $*$ denotes significance level at $p<.05$ 